\title{
Infection prevention and control measures currently applied in South African audiology
}

\author{
Authors: \\ Katerina Ehlert ${ }^{1}$ \\ Alida M. Naude ${ }^{1}$ \\ Affiliation: \\ ${ }^{1}$ Faculty of Health Sciences, \\ University of Limpopo \\ Medunsa Campus, \\ South Africa \\ Correspondence to: \\ Katerina Ehlert \\ Email: \\ katerina.ehlert@ul.ac.za \\ Postal address: \\ PO Box 22129, Lyttelton \\ 0140, South Africa \\ Dates: \\ Received: 25 Feb. 2014 \\ Accepted: 21 June 2014 \\ Published: 11 Nov. 2014 \\ How to cite this article: \\ Ehlert, K., \& Naude, \\ A.M. (2014). Infection \\ prevention and control \\ measures currently applied \\ in South African audiology. \\ South African Journal of \\ Communication Disorders, \\ 61(1), Art. \#55, 10 pages. \\ http://dx.doi.org/10.4102/ \\ sajcd.v61i1.55

\section{Copyright:} \\ (C) 2014. The Authors. \\ Licensee: AOSIS \\ OpenJournals. This work \\ is licensed under the \\ Creative Commons \\ Attribution License.
}

Read online:

Scan this QR code with your smart phone or mobile device to read online.
Background: To counter the global increase in infection-related deaths, infection control has recently developed into an active area of research. Many diseases can be prevented by infection control. In the confines of the audiology clinic, cross-contamination by microorganisms associated with opportunistic infections remains a real concern.

Objective: The primary aim of the study was to ascertain the methods that audiologists in South Africa use to prevent and control the spread of infections during and after consultation with clients.

Method: A survey study was conducted, using a self-administered questionnaire. Fifty currently practising audiologists participated in the study.

Results: The majority $(84 \% ; n=42)$ of respondents acknowledged the importance of hand hygiene for the purpose of infection control, with $76 \%(n=38)$ making use of no-rinse hand sanitisers. Approximately a third of audiologists wear gloves during procedures such as otoscopy and immittance, and while handling hearing aids. Disinfecting audiological equipment seem to be the preferred choice of infection control, with only $60 \%(n=30)$ of respondents sterilising audiological equipment after each individual patient consultation. Less than half of the respondents disinfected touch surfaces and toys in the reception area.

Conclusions: Based on the results, further education and training should focus on measures implemented in infection control, awareness of possible risk factors at work settings, and vaccination as an effective means of infection control.

\section{Introduction}

The second leading cause of death worldwide, after heart disease, is infectious diseases, many of which are spread by contact with unclean hands (World Health Organization [WHO], 2008). Infectious diseases also lead to compromised health and disability. In response to the increase of infection-related deaths, there has recently been a special focus on infection control globally. In the South African context, infection control is of significant concern to audiologists and their clients in all clinical settings (South African Speech-Language-Hearing Association [SASLHA], 2011). The aim of infection control is to eliminate and reduce the spread of infectious diseases (Kemp \& Bankaitis, 2000b).

Over the last 20 years, change in the scope of practice in audiology has improved significantly to include immittance, vestibular procedures, hearing aid technology, the clinical application of evoked potentials and cerumen management. The services provided by audiologists are sought by a diverse population of clients in terms of age, socio-economic position, pre-existing disease, history of pharmaceutical interventions, and other aspects that can affect the integrity of individuals' immune systems and their ability to fend off potentially infectious micro-organisms, subsequently resulting in heightened susceptibility to contracting infection (Clark, Kemp \& Bankaitis, 2003). In the confines of the audiology clinic, cross-contamination with micro-organisms associated with opportunistic infections remains a realistic concern. Opportunistic infections result from ever-present organisms residing in abundance throughout the environment that can cause threatening conditions in patients who are immune compromised (Bankaitis, 2002). As shown by Bankaitis (2002), light to heavy amounts of bacterial and/or fungal growth have been recovered from hearing aid surfaces. Audiologists handling hearing instruments without applying the necessary infection control procedures, inherently increase the potential for disease transmission. Reinsertion of contaminated hearing instruments into the patient's ear canal provides micro-organisms with an easy entry portal into the body. Under the right conditions, such contaminated objects can lead to opportunistic infection that can manifest at the level of the ear canal or gain access into the body, causing a systemic disease. Other objects that may be contaminated and come into direct or indirect contact with patients include headphones, emission 
probe tips, electrodes, otoscope, specula, oto-lights, earmould impression syringes, probe tubes for real-ear measurements, earmoulds and hearing aids (Clark et al., 2003, SASLHA, 2011). Accordingly, it is essential that audiologists are made aware of infectious organisms that could be hazardous to them and their patients. Table 1 summarises the infections relevant to the area of audiology.

There are standard precautionary measures that should be incorporated to control infection in audiology practice (Kemp \& Bankaitis, 2000a). The responsibility of the audiologist includes preventing and controlling disease transmission by means of cleaning, disinfecting and sterilising items and surfaces that are re-used, using protective barriers such as gloves, immunisation to protect themselves against disease, and effective waste management (SASLHA, 2011).

Contact transmission remains the most common means of cross-contamination and potential disease transmission (Kemp \& Bankaitis, 2000b). Contact transmission may occur when the audiologist or the client touches another individual or object, which may encourage unintentional cross-infection via contact transmission. For this reason, proper hand washing is the most effective way to prevent the spread of infections (Kemp \& Bankaitis, 2000a). Hands should be washed before and after contact with a client. In addition, gloves should be worn when there is a risk of exposure to any bodily fluid. Audiological equipment should be cleaned, disinfected and sterilised at regular intervals (Centers for Disease Control and Prevention, 2002; SASLHA, 2011).

Since the turn of the century, the topic of infection control has received special attention by various audiology organisations. The American Academy of Audiology (AAA) issued practice guidelines to its members, addressing the importance and the need for implementing infection control procedures in clinical practice (Clark et al., 2003). The American SpeechLanguage-Hearing Association (ASHA), as well as the South African Speech-Language-Hearing Association (SASLHA), subsequently published similar policy documents. The increased focus on infection control resulted in several studies related to audiology and infection control specifically related to bacterial growth on hearing aids and audiological equipment as well as current infection control trends. The studies indicated the presence of normal flora of the ear as well as isolated pathogens detected on hearing aids, earmoulds and audiological equipment (Ahmad, Etheridge, Farrington \& Baguley, 2007; Bankaitis, 2002; Bankaitis, 2005; Burco, 2007; Clark et al., 2003; Mehdinejad, Khosravi \& Mahmoudabadi, 2010; Powell, Perry \& Meikle, 2003; Sturgulewski, Bankaitis, Klodd \& Haberkamp, 2006). Despite such increased interest in the topic, a survey study on the implementation of infection control guidelines concluded that audiologists were unaware of the potential sources of cross-infection (Kemp \& Bankaitis, 2000a). The majority of surveyed audiologists also indicated that they were unaware of the potential cross-infection by way of virulent pathogens located on standard audiology equipment such as headphones, otoscope specula inserted in the ear canal during ear canal inspection, and probe tips inserted in the ear to assess tympanic membrane mobility. An environment of increased risk of spreading infections and diseases is created by this lack of knowledge, or if knowledge is not implemented adequately.

The extent to which audiologists appreciate the need for infection control, or the importance of integrating infection control principles in the clinical environment in Africa, remains unknown. Developing countries in Africa have the highest infection rate in the world, with South Africa identified as having the highest co-infection rate

TABLE 1: Infectious diseases important to audiology.

\begin{tabular}{|c|c|c|c|}
\hline Disease & Agent & Potential transmission danger & Potential outcome \\
\hline AIDS & Virus & Blood-to-blood contact & Death \\
\hline Chickenpox & Virus & Blood, saliva or mucus (ear drainage) & Conjunctivitis, shingles, encephalitis \\
\hline Common cold & Virus & $\begin{array}{l}\text { Blood, saliva, mucus (e.g. infected client sneezes on counter, audiologist touches } \\
\text { counter, touches nose, then breathes on others in the office) }\end{array}$ & Temporary disability \\
\hline Cytomegalovirus & Virus & Blood, saliva, mucus (e.g. touch infected toy) & Birth defects, death \\
\hline Hepatitis A & Virus & Oral, faecal( e.g. failure to wash hands after contact) & Disability, liver damage \\
\hline Hepatitis B & Virus & Blood, saliva, mucus (e.g. handling cerumen containing dried blood) & Chronic carrier, chronic disability, death \\
\hline Herpes simplex-1 & Virus & Blood, saliva, mucus, exudations from sores & Temporary discomfort, herpetic conjunctivitis \\
\hline Herpes zoster (shingles) & Virus & Blood, saliva, mucus (e.g. touch blister) & Disability \\
\hline Infectious meningitis & Virus or bacteria & Blood, saliva, mucus (e.g. contact with infected mucus (ear drainage)) & Temporary disability \\
\hline Influenza & Virus & Saliva, mucus, respiratory droplets & Temporary disability, death \\
\hline Legionellosis & Bacteria & Respiratory droplets & Temporary disability, death \\
\hline Measles & Virus & Saliva, mucus & $\begin{array}{l}\text { Congenital defects, temporary disability, } \\
\text { encephalitis }\end{array}$ \\
\hline Mumps & Virus & Respiratory droplets & Temporary disability, sterility (men) \\
\hline Pediculosis & Lice & Lice transported from scalp via combs and hats & Temporary disability, itching and scratching \\
\hline Pneumonia & Virus, bacteria & Blood, respiratory droplets & Temporary disability, death \\
\hline Staphylococcus & Bacteria & Saliva, mucus (e.g. audiologist handles ear mould or speculum prior to disinfecting) & Skin lesions, death \\
\hline Streptococcus & Bacteria & Blood, saliva, mucus, respiratory droplets & Heart and kidney problems, death \\
\hline Tuberculosis & Bacteria & Respiratory droplets, saliva & Disability, death \\
\hline
\end{tabular}

Source: Adapted from Kemp, R.J., Roeser, R.J., Pearson, D.W. \& Ballachandra, B.B. (1996). Infection control for the professions of audiology and speech language pathology. Iles Publications, Olathe.

ITEs, in-the-ear devices 
(National Intelligence Council, 2000). The high co-infection rate is related to most clinics being in rural areas that face challenges such as a lack of resources, including water and disinfectant materials. With research (Sarma \& Ahmed, 2010) showing that healthcare-associated infections in developing countries (such as South Africa) can exceed 25\%, compared with developed countries, it is clear that infection control is an issue of considerable importance that highlights the significance of a study on infection control at the present time, to curb the ever-increasing rate of cross-contamination in South Africa. Therefore the research question arises: what is the application of infection control measures in audiology practice in South Africa?

\section{Method}

\section{Aims}

The main aim of the study was to determine how specific infection control measures were applied in audiology clinical settings in South Africa. Secondary objectives were to determine (1) which infection control measures are applied in audiology practices; (2) how frequently specific infection control measures are applied in audiology practices; (3) current compliance with infection control measures in accordance with measures required by the South African Department of Health; (4) possible needs for further continued professional development in the area of infection control; and (5) guidelines for the development of future programmes focused on infection control.

\section{Participants}

\section{Inclusion criteria}

The criteria for subject selection were that respondents had to be practising at the time of the study, registered with the Health Professions Council of South Africa (HPCSA), and literate in English.

\section{Sample}

Purposive sampling was used because this method is based on the judgment of researchers regarding the characteristics of a representative sample (Leedy \& Ormrod, 2010). Fifty practising audiologists participated in the study, comprising 15 African women, 33 Caucasian women and 2 Caucasian men. The participants represented all nine provinces, namely Northern Cape $(n=5)$, Eastern Cape $(n=7)$, Free State $(n$ $=2)$, Western Cape $(n=9)$, Limpopo $(n=10)$, North West $(n=2)$, KwaZulu-Natal $(n=5)$, Mpumalanga $(n=5)$ and Gauteng $(n=5)$. Fifty-two percent $(n=26)$ of this sample represented service delivery in rural areas. The mean age of the audiologists was 37 years. The audiologists are referred to as the respondents.

\section{Research method and design}

A quantitative research approach was employed for the purpose of this study, and a survey (questionnaire) was used to conduct the descriptive study.

\section{Data collection}

The questionnaire consisted of the following sections: biographic information; infection control measures in audiology; transmission of infectious diseases; knowledge regarding infection control; application measures in infection control; and personal views. Both open- and closed-ended questions were included. During closed-ended questions, respondents were requested to select one of the provided answers, while respondents had to formulate their own answers to open-ended questions (Czaja \& Blair, 2005). Answers to the closed-ended questions were easily comparable, coded statistically and analysed. Questionnaires and consent letters were emailed and delivered by hand to the respondents. Questionnaires were returned by email or delivered by hand. From the 200 questionnaires distributed to audiologists practising in South Africa, 50 respondents (25\%) participated in the study, which is an acceptable return rate for questionnaires (Champion \& Sear, 1999).

\section{Ethical considerations}

Approval was obtained from the Medunsa Research Ethics Committee (MREC). For the purposes of the current study, confidentiality and anonymity of respondents was maintained by ensuring that no names appeared on the completed questionnaires.

\section{Reliability, validity and bias}

To ensure validity of the measurements, the researchers considered the face validity of the questionnaire (Leedy \& Ormrod, 2010). During the pilot study, two audiologists recognised for their expertise in infection control measures were asked to complete the questionnaire and evaluate if the instrument measures matched the outcomes of the study, if the questions were phrased appropriately, and if the options for responding seemed appropriate. This information was important as incorrect wording of questions can lead to survey bias. As bias can result from unreliable and/or invalid questions, the experts were asked to identify questions that were subject to various interpretations, or invalid questions that could push the respondent toward a certain type of answer, thus creating bias in predictable ways (Penwarden, 2013). Assessment of the wording of questions, the type of questions used, the design of the questionnaire, and the survey structure was essential to minimise response bias. The two expert audiologists were asked to highlight loaded terms, compound questions, and excessively long phrases. The questionnaire questions were comprehensive to address the objectives, but were limited to closed-ended questions, and each question included instructions on how to answer the question. Close-ended questions greatly simplify coding and analysis later on (Penwarden, 2013). The two experts were also asked to evaluate the content validity of the questionnaire with reference to the known components involved in infection control measures for audiologists. Suggested changes were effected before the questionnaires were distributed. The researchers also considered criterion validity by comparing the questionnaire with other measures 
of infection control in the literature (Leedy \& Ormrod, 2010). Reliability of the study was established by describing the methodology in detail to ensure that similar results would be found, should the study be repeated. The other aspect of reliability that was considered was consistency among the questions (Penwarden, 2013). The respondents' answers were checked to ensure that they were fairly consistent and correlated with other questions in other categories of the questionnaire. Bias was further minimised by addressing over-generalisation, over-comparison and unfounded conclusions based on the research data collected during the study, and that the researchers interpreted the respondent ideas appropriately by writing down only a summary of the answers with the consultation of the statistician (Leedy \& Ormrod, 2010).

\section{Data analysis}

Descriptive statistics formed the basis of the data analysis procedure. The data collected from the questionnaires were encoded and then tabulated and analysed using the South African Statistics (SAS) Software, Version 9.1.3 for Windows ${ }^{\circledR}$. Averages, means and statistical significances were used to analyse the data.

\section{Results and discussion Infection control measures applied in audiology practices}

Hand hygiene represents the single most important procedure for effectively limiting the spread of infectious diseases, and is seen as a minimum requirement for performing tasks in audiology (Kemp \& Bankaitis, 2000a; SASLHA, 2011). It is one of the most critical components of a basic infection control programme and is therefore addressed first in terms of reporting results related to the specific outcomes of this study. The results of the study are presented in Table 2.

The results showed that most $(84 \% ; n=42)$ respondents acknowledged the importance of hand hygiene for the purpose of infection control. These respondents indicated that they wash their hands after contact with a patient, which is in line with the $82 \%$ reported in the study conducted by Burco (2007). This finding is also in line with the international focus on education in the area of infection control and SASLHA guidelines. It is interesting, however, that although not statistically significant according to the $t$-test $(p>0.05)$, only $62 \%(n=32)$ of respondents washed their hands before a patient session. The results regarding hand washing after bathroom use is of great concern. Only 78\% $(n=36)$ of respondents reported that they always wash their hands after using the bathroom. The implication is that respondents expose themselves and their patients to infections, as bathrooms are associated with various infections. It is also interesting that, although $2 \%(n=1)$ of respondents did not report hand hygiene to be important, some infection control guidelines were still followed on occasion.

Since hand washing is regarded as the most effective method for reducing the spread of diseases, especially in healthcare practices, hands should be washed with hospital antibacterial soap and water before and after each patient (Kemp \& Bankaitis, 2000a). The fact that more respondents preferred to wash their hands after seeing a patient than before, suggests that respondents have the perception that they can only contract diseases from their patients but not vice versa. Respondents are not following effective hand hygiene in accordance with the guidelines for effective control measures provided by SASLHA and Kemp and Bankaitis (2000a), and this could result in cross-infection from audiologist to patient and vice versa. Only $2 \%(n=1)$ of respondents did not consider hand hygiene effective for infection control. Although this is a low number, it may have an influence on the application of infection control. Hand hygiene is receiving a great deal of attention globally and is an effective way of reducing the spread of diseases, as mentioned previously.

The use of hand sanitisers has been approved as effective for hand hygiene and reduces the number of bacteria more effectively than washing soap and even antibacterial soap (Bankaitis \& Kemp, 2000; Hand Hygiene Resource Center, 2002). Sanitisers can be used with ease and convenience compared with soap and water. During the study, it was determined that most respondents $(76 \% ; n=38)$, have access to a no-rinse hand sanitiser in their clinical setting, which is higher than the reported 50\% by Almani (1999). This is seen as a positive response, as no-rinse hand sanitisers can be easily and effortlessly applied before and after seeing each patient (Bankaitis \& Kemp, 2000). The results, however, indicate that $14 \%(n=7)$ of respondents did not have access to a no-rinse hand sanitiser, possibly owing to the cost involved or easy access to water. However, since most respondents practise in rural areas where they face challenges such as a lack of running water, this can increase the chances of cross-infection. Where there is no running water and respondents also do not have access to no-rinse hand sanitisers, respondents cannot practise proper infection control measures. In addition to

TABLE 2: Hand washing practices of respondents in clinical settings.

\begin{tabular}{lllll}
\hline Hand hygiene practices & Frequency of hand hygiene practices & Always (\%) & Sometimes (\%) & Never (\%) \\
\hline Hand washing & After contact with patient & 84 & 16 & 30 \\
& Before contact with patient & 62 & 12 & 8 \\
& After using bathroom & 78 & 8 & 10 \\
& After ear mould impression & 80 & 2 & 26 \\
& After cerumen management & 72 & 16 & 6 \\
\hline
\end{tabular}


hand washing and hand sanitisers, gloves are a well-known means of infection control and effective in preventing audiologists from handling used equipment with bare hands, which could increase cross-infections (SASLHA, 2011).

The results showed that less than half of the respondents used gloves when performing the audiological procedures mentioned in Table 3. This could be because there is no potential risk of cross-infection and that gloves are only used when there is a potential risk of cross-infection. Only $30 \%$ of the respondents indicated that they always wore gloves. It is concerning that $36 \%$ of the respondents did not see the significance of wearing gloves when performing otoscopy. The number of respondents that indicated that they never wore gloves during otoacoustic emissions (OAE) testing, immittance testing and hearing aid fitting is also of great concern as these procedures increase the risk of crossinfection from patient to patient, and patient to audiologist, and the other way round (Kemp \& Bankaitis, 2000b). When comparing the results on impression taking with the results of Burco (2007), less than $9 \%$ of the respondents used latex gloves during earmould impression procedures in both studies. This is a matter of concern as the earmould impressions removed from the ear canal can be contaminated with cerumen and other micro-organisms that may reside in the ear canal (Bankaitis \& Kemp, 2002). These respondents increase the potential risk of cross-infection and spread of diseases which can occur when handling earmould impressions with bare hands. The results showed a decrease in the application of gloves when handling hearing aids from $39 \%$ in the Burco (2007) study compared with $16 \%(n=8)$ in this study. This decrease could possibly be attributed to respondents in this study not seeing hearing aids as potential carriers of infection.

Effective implementation of infection control measures also includes sterilisation of equipment and apparatus used during audiological practice. Sterilisation is an effective measure of infection control as it kills $100 \%$ of the vegetative micro-organisms and endospores (Bankaitis \& Kemp, 2005; SASLHA, 2011).

The results showed that more than $60 \%(n=30)$ of the respondents preferred to sterilise audiological equipment after each individual patient consultation. It is alarming that $34 \%(n=17)$ of the respondents only sterilised equipment once a week. Regardless of the reasons for irregular sterilisation of equipment, it remains in conflict with ethical and infection control guidelines which focus on putting patients first and practising in their best interest (SASLHA, 2011).

Implementation of effective infection control measures is crucial for any health profession, requiring professionals to adhere to the guidelines stipulated by SASLHA (2011). This study investigated and reported methods of minimising the spread of infections and infectious diseases in audiology practice; the results are presented in Figure 2.

The majority $(90 \% ; n=45)$ of respondents disinfected headphones in audiology clinical settings and cleaned the audiometer top. However, a few respondents did not see the

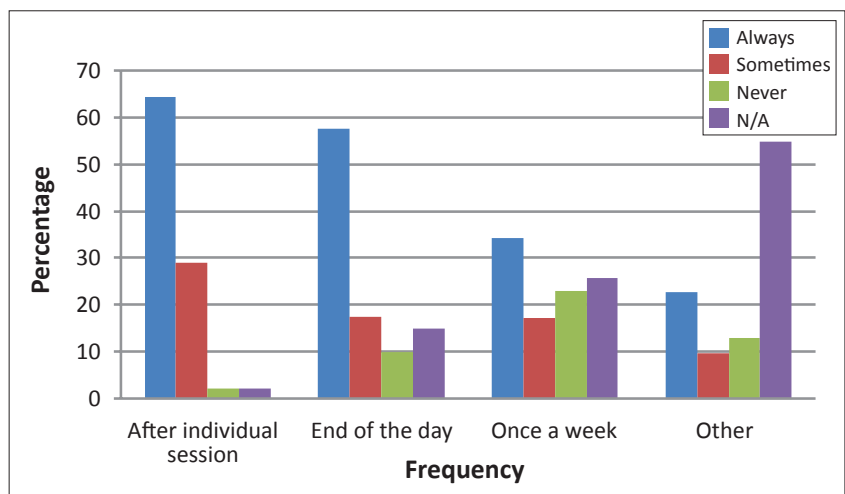

FIGURE 1: Frequency of sterilising audiology equipment.

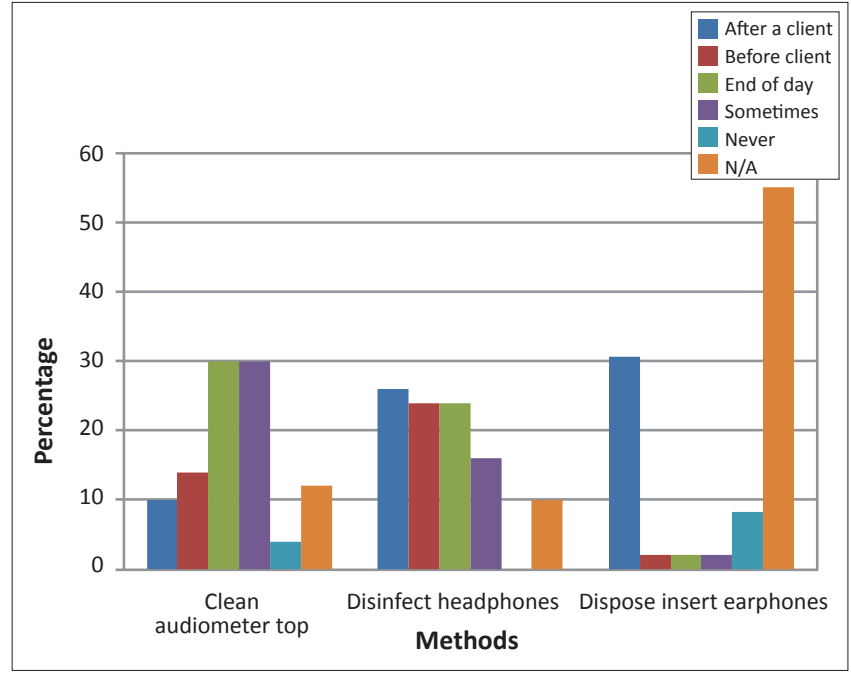

FIGURE 2: Methods of minimising infectious disease in audiology practices.

TABLE 3: Application of latex gloves

\begin{tabular}{|c|c|c|c|c|c|}
\hline Application of gloves & Audiological procedures & Always (\%) & Sometimes (\%) & Never (\%) & N/A (\%) \\
\hline \multirow[t]{4}{*}{ Gloves during procedures } & Otoscope & 30 & 30 & 36 & 4 \\
\hline & Immittance & 30 & 34 & 34 & 2 \\
\hline & Handling hearing aids & 16 & 30 & 48 & 6 \\
\hline & OAE probes & 29.8 & 23.4 & 29.8 & 17 \\
\hline \multirow[t]{4}{*}{ When are gloves worn? } & Cerumen management & - & - & - & 48 \\
\hline & Draining ears & - & - & - & 10 \\
\hline & Impression taking & - & - & - & 6 \\
\hline & Presence of blood & - & - & - & 36 \\
\hline
\end{tabular}

N/A, not applicable; OAE, otoacoustic emissions. 
significance of cleaning an audiometer. Although cleaning removes gross contamination from an object or surface, it does not kill germs, but it is a precursor for sterilising and disinfecting (SASLHA, 2011). The results showed that $10 \%$ $(n=5)$ of the respondents did not disinfect headphones, and $64 \%(n=32)$ did not dispose of insert earphones. This practice is hazardous to patients because it increases the chances of cross-infection from patient to patient. Unfortunately, the question did not allow respondents to elaborate on the reason why they did not dispose of insert earphones or whether they re-used them or not. When insert earphones are used from patient to patient, it puts the patient at risk of contracting infections as micro-organisms may grow on the earphones, causing cross-infections. It is a well-known fact that some audiologists wash insert earphones with soap and water or products such as Milton. This practice is not recommended, as the effectiveness of these products is reduced by blood and bodily fluids (Bankaitis \& Kemp, 2005).

Disinfection is acceptable for items that are in contact with blood and infectious substances; such items should be disinfected before handling and immediately after use (Bankaitis \& Kemp, 2005). The results for applied methods of minimising the spread of infections and infectious diseases specifically in components of mechanical instruments used in audiology practice are presented in Figure 3.

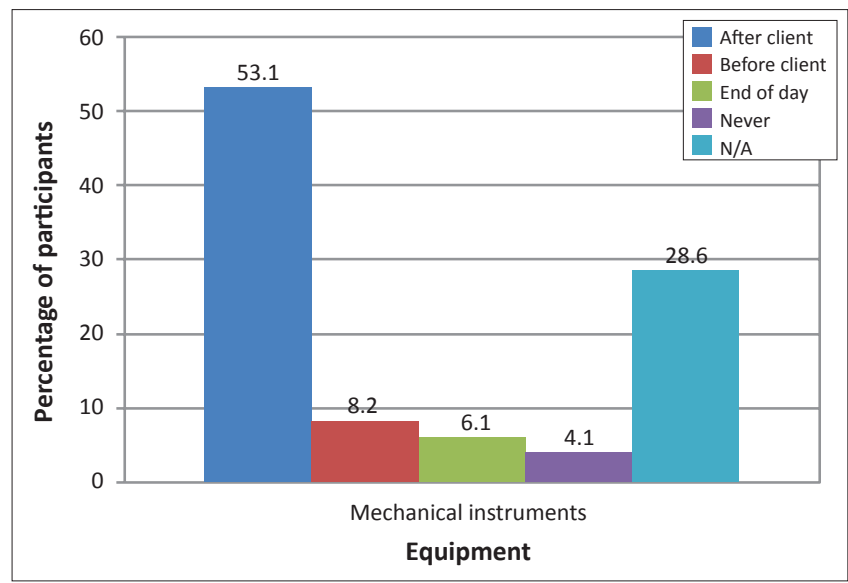

FIGURE 3: Method of minimising infectious disease.

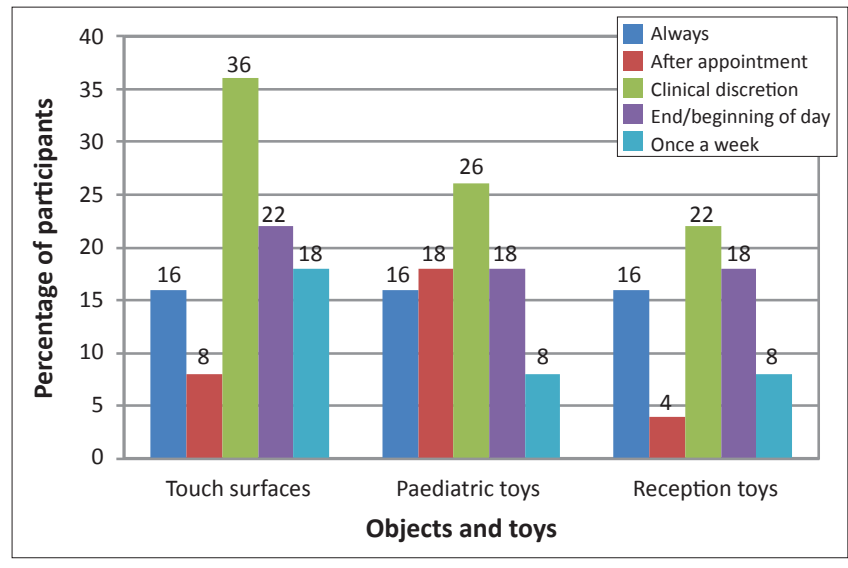

FIGURE 4: Frequency of disinfection of objects and toys in audiology practices.
Mechanical instruments in audiology usually comprise the equipment used during cerumen management, such as curettes and forceps. Just over half of the respondents $(54 \% ; n=27)$ disinfected mechanical equipment. It is of great concern that $34 \%(n=17)$ of respondents did not disinfect their mechanical equipment, which puts their patients at risk of cross-transmission of infectious diseases, as mentioned previously. There is a decrease from $45 \%(n=32)$ to $32 \%(n=16)$ in the results when compared with the Burco (2007) study.

Apart from audiological equipment, it is also important to disinfect objects such as office toys as they are often the cause of transferring infections (Kemp \& Bankaitis, 2000a). The present study investigated the frequency of disinfecting objects and toys in audiology practices; the results are presented in Figure 4.

The results show that less than half of respondents disinfected touch surfaces and toys, and then only when there was visible contamination. Although this figure is higher than that reported by Burco (2007), it is not acceptable according to professional infection control guidelines (SASLHA, 2011). Reception toys should be disinfected daily because children may put them in their mouth, and saliva is a fertile source of bacteria. Other touch surfaces such as desks, magazine tables, chairs and door handles need to be disinfected regularly (Kemp \& Bankaitis, 2000a). The responses from respondents in this study as well as that of Burco (2007) indicate the need to also revise the professional code of ethics. Professionals commit themselves to principles such as non-maleficence, trust and social responsibility; these should be considered key elements in audiology practice.

\section{Conclusion and recommendations}

Although no previous findings related to South Africa were available on audiology-specific infection control that could be used to compare the results, the present study assessed the current application of infection control measures in audiology practices in South Africa. The results from this study also provided individual opinions of the infection control application measures, identified areas of concern and whether audiologists are in danger of cross-infection or causing cross-infection, and brought awareness to audiologists about the importance of applying measures to prevent infections. Specific areas of infection control for future research were also identified.

If audiologists are not alert regarding possible communicable diseases in their clinical settings, infection control measures will be compromised. In assisting such audiologists to effectively practice infection control, the following steps should be taken: (1) annual training and review of infection control, (2) CPD workshops on the topic of infection control, (3) adequate education and training during undergraduate studies, (4) every audiology clinical setting should have infection control guidelines, (5) audiologists should receive training on how to apply infection control measures to specific diseases such as TB and the H1N1 virus, (6) training on handling an exposure incidence, and (7) disposing of waste materials. As the practice of audiology and speech- 
language pathology involves and requires a notable degree of patient contact, patients and clinicians are exposed to an environment in which a variety of contaminated objects may come into direct or indirect contact with numerous patients. In the delivery of any health-related service, it is the health professional's responsibility to ensure the safety of their patients. It is imperative that audiologists provide patients with diagnostic and treatment environments that are designed to minimise or eliminate potential transmission of disease. Audiologists must be professionally and socially responsible by being diligent in their efforts to control the spread of infectious disease within the context of the entire clinical setting.

Indications for future research include repeating the study on a larger population so as to generalise the data to the entire field, to obtain statistical data on infection control practices in the field as a whole. It would also be of value to develop a training programme and evaluate its effect on audiologists. A study testing for micro-organisms on different audiological equipment could also be of value to increase audiologists' awareness of the importance of infection control.

\section{Acknowledgements}

Portia Mpudi, Solly Ngwanathi, Alfa Nkuna and Liepollo Ntlhakana are thanked for their valuable contribution to the original study.

\section{Competing interests}

The authors declare that they have no financial or personal relationship(s) that may have inappropriately influenced them in writing this article.

\section{Authors' contributions}

K.N. (University of Limpopo) and A.M.N. (University of Limpopo) contributed equally to the article.

\section{References}

Ahmad, N., Etheridge, C., Farrington, M., \& Baguley, D.M. (2007). Prospective study of the microbiological flora of hearing aid moulds and the efficacy of current cleaning techniques.J Laryngol Otol, 121(2), 110-113.http://dx.doi.org/10.1017/ S0022215106002222
Almani, A.M. (1999). Current trends and future needs for practices in audiologic infection control. J Am Acad Audiol, 10(3), 151-159.

Bankaitis, A.U. (2002). What's growing on your patient's hearing aids? A study gives you an idea. Hearing Journal, 55(6), 48-53. http://dx.doi.org/10.1097/01. HJ.0000293278.53653.ac

Bankaitis, A.U. (2005). Hearing aids: Lick 'em and stick 'em? Sticking hearing aids in the mouth is not a good idea. Audiology Today, 17(6), 2-3.

Bankaitis, A.U., \& Kemp, R.J. (2002). Hearing aid related infection control. Strategies for selecting and verifying hearing aid fittings. In M. Valente (Ed.), Hearings aids: Standards, options and limitations (2nd edn.) (pp. 369-383). New York: Thieme Publishing Group.

Bankaitis, A.U., \& Kemp, R.J. (2005). Infection control in the audiology clinic (2nd edn). St Louis: Auban.

Burco, A. (2007). Current infection control trends in audiology, Independent studies and capstones. Paper 287, Program in Audiology and Communication Sciences, Washington University School of Medicine. Retrieved May 07, 2012, from http:// digitalcommons.wustl.edu/pacs_capstones/287

Centers for Disease Control and Prevention. (2002). Guideline for hand hygiene in health-care setting. MMWR, 51(RR16), 1-44.

Champion, D.J., \& Sear, A.M. (1999). Questionnaire response rate: A methodological analysis. Social Forces, 47(3), 335-339. http://dx.doi.org/10.2307/2575033

Clark, J.G., Kemp, R.J., \& Bankaitis, A.U. (2003). Infection control in audiology practice. Audiology Today, 15(5), 12-19.

Czaja, R., \& Blair, J. (2005) Designing surveys. A guide to decisions and procedures (2nd edn.). Sage Publications, Thousand Oaks.

Hand Hygiene Resource Center. (2002). Selecting the right alcohol-based hand rub for your health care facility. Retrieved September 13, 2012, from http://www. handhygiene.org/downloads/Selecting.pdf

Kemp, R.J., \& Bankaitis, A.E. (2000a). Infection control in audiology. Audiology Online, 04 June.

Kemp, R.J., \& Bankaitis, A.E. (2000b). Infection control for audiologists. In H. HosfordDunn, R. Roeser \& M. Valente (Eds.). Audiology diagnosis, treatment, and practice management (Vol. 3, pp. 257-279). New York: Thieme Publishing Group.

Kemp, R.J., Roeser, R.J., Pearson, D.W., \& Ballachandra, B.B. (1996). Infection control for the professions of audiology and speech language pathology. Olathe: lles Publications.

Leedy, P.D., \& Ormrod, J.E. (2010). Practical research: Planning and design (9th edn.). Upper Saddle: Pearson Education/Merill.

Mehdinejad, M., Khosravi, A.D., \& Mahmoudabadi, A.Z. (2010). Study of bacterial flora in children with hearing aid moulds in Ahvaz, Iran. Pakistan Journal of Biological Sciences, 13(5), 245-248. http://dx.doi.org/10.3923/pjbs.2010.245.248

National Intelligence Council. (2000). The global infectious disease threat and its implications for the United States. Retrieved May 07, 2012, from http://www.dni. gov/nic/special_globalinfectious.html

Penwarden, R. (2013). Survey design. Retrieved June 14, 2014, from http:// fluidsurveys.com/14 June 2014

Powell, S., Perry, J., \& Meikle, D. (2003). Microbial contamination of non-disposable instruments in otolaryngology out-patients. J Laryngol Otol, 117, 122-125. http:// dx.doi.org/10.1258/002221503762624567

Sarma, J.B., \& Ahmed, G.U. (2010). Infection control with limited resources: Why and how to make it possible. Indian J Med Microbiol, 28(1), 11-16. http://dx.doi. org/10.4103/0255-0857.58721

South African Speech-Language-Hearing Association (SASLHA). (2011). Guidelines infection control: Guidelines for speech-language therapists and audiologists regarding infection control. Retrieved June 06, 2012, from http://www.saslha. co.za

Sturgulewski, S.K., Bankaitis, A.U., Klodd, D.A., \& Haberkamp, T. (2006). What's stil growing of your patients' hearing aids? Hearing Journal, 59, 45-48. http://dx.doi. org/10.1097/01.HJ.0000285827.98823.87

World Health Organization (WHO). (2008). The global burden of disease: 2004 update. Retrieved 02, November 2012, from http://www.who.int/evidence/bod/18\%20 July\%202012 


\section{Appendix}

\section{Questionnaire}

Please select the option that most accurately reflects your opinion or practice.

Click in the Choose Item box and a drop-down menu will appear; then click on it to choose your answer.

\section{SECTION A:}

\section{CURRENT SETTING OF PRACTICE}

Q1: In which setting are you currently practising (tick the correct answer)?

\begin{tabular}{|l|l|}
\hline Private practise urban & \\
\hline Private practise rural & \\
\hline Rural clinic & \\
\hline Urban clinic & \\
\hline Government hospital & \\
\hline Private hospital & \\
\hline Government school & \\
\hline University & \\
\hline Manufacturer & \\
\hline
\end{tabular}

Q2: Please indicate the number of years at your primary work setting indicated above (tick the correct answer).

\begin{tabular}{|l|l|}
\hline$<1$ year & \\
\hline 1 to 5 years & \\
\hline 6 to 10 years & \\
\hline $11-15$ years & \\
\hline $16-20$ years & \\
\hline$>20$ years & \\
\hline
\end{tabular}

Q3: What patient population do you currently serve at your primary work setting (tick the correct answer)?

\begin{tabular}{|l|l|}
\hline Adults only & \\
\hline $\begin{array}{l}\text { Mainly adults ( } 80 \% \text { or more) with some paediatric patients (up } \\
\text { to } 20 \% \text { ) }\end{array}$ & \\
\hline Fairly balanced representation of adults and paediatric patients & \\
\hline $\begin{array}{l}\text { Mainly paediatric patients (80\% or more) with some adults } \\
\text { patients }\end{array}$ & \\
\hline Paediatric only & \\
\hline Don't see patients & \\
\hline
\end{tabular}

Q4: In a typical week, what services do you personally provide (more than one may be chosen, tick the correct answer/s)?

\begin{tabular}{|l|l|}
\hline Pure tone audiometer & \\
\hline Otoscopy & \\
\hline Immitance audiometer & \\
\hline Otoacoustic emissions & \\
\hline Auditory brainstem response & \\
\hline ENG/VNG & \\
\hline Hearing aid dispensing & \\
\hline Cohlear implants & \\
\hline Central auditory processing & \\
\hline Cerumen management & \\
\hline Other evoked potentials (please specify) & \\
\hline
\end{tabular}

\section{SECTION B:}

\section{INFECTION CONTROL MEASURES IN AUDIOLOGY}

Q5(a): Do you have access to a sink with running water at your current professional setting (tick the correct answer)?

\begin{tabular}{|l|l|}
\hline Yes & \\
\hline No & \\
\hline Unsure & \\
\hline
\end{tabular}

If you answered Yes in no. 5(a), please answer 5(b); otherwise, proceed to question 7.

Q5(b): How far is the sink in relation to your consultation area (tick the correct answer)?

\begin{tabular}{|l|l|}
\hline$<50$ meters & \\
\hline 50 to 100 meters & \\
\hline$>100$ meters & \\
\hline
\end{tabular}

Q6: Do you have access to no-rinse hand sanitisers (tick the correct answer)?

\begin{tabular}{|l|l|}
\hline Yes & \\
\hline No & \\
\hline Unsure & \\
\hline
\end{tabular}

Q7: Do you perform the following actions in your work setting (tick the correct answers)?

\begin{tabular}{|l|l|}
\hline (a) Clean the audiometer tap & \\
\hline After a client & \\
\hline Before a client & \\
\hline At the end of the day & \\
\hline Sometimes & \\
\hline Never & \\
\hline Not applicable & \\
\hline If you selected 'Sometimes' please explain when? & \\
& \\
\end{tabular}

\begin{tabular}{|l|l|}
\hline (b) Disinfect headphones. & \\
\hline After a client & \\
\hline Before a client & \\
\hline At the end of the day & \\
\hline Sometimes & \\
\hline Never & \\
\hline Not applicable & \\
\hline If you selected 'Sometimes' please explain when? & \\
\end{tabular}

\begin{tabular}{|l|l|}
\hline (c) Dispose of insert earphones. & \\
\hline After a client & \\
\hline Before a client & \\
\hline At the end of the day & \\
\hline Sometimes & \\
\hline Never & \\
\hline Not applicable & \\
\hline If you selected 'Sometimes' please explain when? & \\
& \\
\end{tabular}




\begin{tabular}{|l|l|}
\hline \multicolumn{2}{|l|}{ (d) Sterilise individuals' probe-tips (immittance or OAE). } \\
\hline After a client & \\
\hline Before a client & \\
\hline At the end of the day & \\
\hline Sometimes & \\
\hline Never & \\
\hline Not applicable & \\
\hline If you selected 'Sometimes' please explain when? & \\
\end{tabular}

\begin{tabular}{|l|l|}
\hline (e) Sterilise otoscope specula. & \\
\hline After a client & \\
\hline Before a client & \\
\hline At the end of the day & \\
\hline Sometimes & \\
\hline Never & \\
\hline Not applicable & \\
\hline If you selected 'Sometimes' please explain when? & \\
\end{tabular}

\begin{tabular}{|l|l|}
\hline (e) Sterilise real-ear probe tube. & \\
\hline After a client & \\
\hline Before a client & \\
\hline At the end of the day & \\
\hline Sometimes & \\
\hline Never & \\
\hline Not applicable & \\
\hline If you selected 'Sometimes' please explain when? & \\
\end{tabular}

\begin{tabular}{|l|l|}
\hline (f) Disinfect mechanical instruments used for cerumen removal. \\
\hline After a client & \\
\hline Before a client & \\
\hline At the end of the day & \\
\hline Sometimes & \\
\hline Never & \\
\hline Not applicable & \\
\hline If you selected 'Sometimes' please explain when? & \\
\end{tabular}

\begin{tabular}{|l|l|}
\hline (g) Lower temperatures in the work place to reduce the spread of infection. \\
\hline After a client & \\
\hline Before a client & \\
\hline At the end of the day & \\
\hline Sometimes & \\
\hline Never & \\
\hline Not applicable & \\
\hline If you selected 'Sometimes' please explain when? & \\
\end{tabular}

Q8: What items do audiologists handle that exposes them to infectious diseases (tick the correct answers)?

\begin{tabular}{|l|l|}
\hline (a) Oto-lights & \\
\hline Yes & \\
\hline No & \\
\hline Unsure & \\
\hline
\end{tabular}

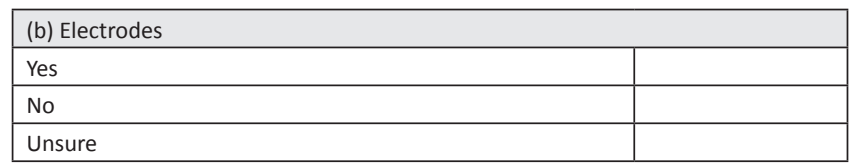

\begin{tabular}{|l|l|}
\hline (c) Ear moulds & \\
\hline Yes & \\
\hline No & \\
\hline Unsure & \\
\hline
\end{tabular}

\begin{tabular}{|l|l|}
\hline (d) Needles & \\
\hline Yes & \\
\hline No & \\
\hline Unsure & \\
\hline
\end{tabular}

\begin{tabular}{|l|l|}
\hline (d) Probes & \\
\hline Yes & \\
\hline No & \\
\hline Unsure & \\
\hline
\end{tabular}

\begin{tabular}{|l|}
\hline (d) other \\
\hline Please specify: \\
\hline
\end{tabular}

Q9: Do you wear gloves when handling the following audiological objects (tick the correct answers)?

\begin{tabular}{|l|l|l|l|l|}
\hline Audiological objects & Always & Sometimes & Never & n/a \\
\hline Otoscope & & & & \\
\hline Immittance probes & & & & \\
\hline Hearing aids & & & & \\
\hline OAE probes & & & & \\
\hline
\end{tabular}

\section{SECTION C:}

\section{APPLICATION MEASURES IN INFECTION CONTROL}

\section{Q10: Do you sterilise equipment (tick the correct answers)?}

\begin{tabular}{|l|l|l|l|l|}
\hline Scenario & Always & Sometimes & Never & n/a \\
\hline After individual sessions & & & & \\
\hline At the end of the day & & & & \\
\hline Once a week & & & & \\
\hline Other & & & & \\
\hline If you selected 'Other' please explain when? & & & \\
\hline
\end{tabular}

Q11: Adequate hand hygiene is crucial in infection control (tick the correct answer).

\begin{tabular}{|l|l|}
\hline Always & \\
\hline Sometimes & \\
\hline Never & \\
\hline Not applicable & \\
\hline If you selected 'Sometimes' please explain when? & \\
& \\
& \\
\end{tabular}

If you answered 'Always' or 'Sometimes' in question 11, please answer question 12. Otherwise, proceed to question 13. 


\section{Q12: What do you consider as adequate hand hygiene?}

Q13: Is it acceptable to use a bar of soap for hand hygiene (tick the correct answer)?

\begin{tabular}{|l|l|}
\hline Always & \\
\hline Sometimes & \\
\hline Never & \\
\hline Not applicable & \\
\hline
\end{tabular}

Q14: Do you wash your hands after removal of gloves (tick the correct answer)?

\begin{tabular}{|l|l|}
\hline Always & \\
\hline Sometimes & \\
\hline Never & \\
\hline Not applicable & \\
\hline
\end{tabular}

Q15: Do you wash your hands before contact with every individual client (tick the correct answer)?

\begin{tabular}{|l|l|}
\hline Always & \\
\hline Sometimes & \\
\hline Never & \\
\hline Not applicable & \\
\hline
\end{tabular}

Q16: Do you wash your hands after contact with each individual client (tick the correct answer)?

\begin{tabular}{|l|l|}
\hline Always & \\
\hline Sometimes & \\
\hline Never & \\
\hline Not applicable & \\
\hline
\end{tabular}

Q17: Do you wash your hands after using the bathroom basin (tick the correct answer)?

\begin{tabular}{|l|l|}
\hline Always & \\
\hline Sometimes & \\
\hline Never & \\
\hline Not applicable & \\
\hline
\end{tabular}

Q18: Do you wash your hands after ear mould impression procedures (tick the correct answer)?

\begin{tabular}{|l|l|}
\hline Always & \\
\hline Sometimes & \\
\hline Never & \\
\hline Not applicable & \\
\hline
\end{tabular}

Q19: Do you wash your hands after cerumen management (tick the correct answer)?

\begin{tabular}{|l|l|}
\hline Always & \\
\hline Sometimes & \\
\hline Never & \\
\hline Not applicable & \\
\hline
\end{tabular}

Q20: How often are touch surfaces, such as countertops, armchair rests, or counselling table surfaces disinfected (tick the correct answer/s)?

\begin{tabular}{|l|l|}
\hline Never & \\
\hline After each patient appointment & \\
\hline As needed based on the discretion of the clinician & \\
\hline At the beginning and/or end of the day & \\
\hline Once a week & \\
\hline Once a month & \\
\hline
\end{tabular}

Q21: How often do you disinfect toys used during pediatric hearing assessment (tick the correct answer/s)?

\begin{tabular}{|l|l|}
\hline Never & \\
\hline After each patient appointment & \\
\hline As needed based on the discretion of the clinician & \\
\hline At the beginning and/or end of the day & \\
\hline Once a week & \\
\hline Not applicable & \\
\hline Don't see paediatric patients & \\
\hline
\end{tabular}

Q22: How often do you disinfect toys that reside in the waiting room or reception area (tick the correct answer/s)?

\begin{tabular}{|l|l|}
\hline Never & \\
\hline After each patient appointment & \\
\hline As needed based on the discretion of the clinician & \\
\hline At the beginning and/or end of the day & \\
\hline Once a week & \\
\hline Once a month & \\
\hline Not applicable & \\
\hline
\end{tabular}

Thank you for your input. We appreciate your participation in this study. 